\title{
Chemical composition and sensory characteristics of Feta cheese fortified with iron and ascorbic acid
}

\author{
Maryam Jalili ${ }^{1}$
}

Received: 2 September 2015 / Accepted: 22 January 2016/

Published online: 12 February 2016

C) INRA and Springer-Verlag France 2016

\begin{abstract}
Feta cheese is an excellent source of calcium and protein, but as typical dairy products, it contains very low amount of iron. The present study was designed to investigate the effect of iron fortification on quality of Feta cheese. The cheese samples were made from cow milk and fortified with iron compounds, namely ferrous sulfate $\left(\mathrm{FeSO}_{4}\right)$, ferric chloride $\left(\mathrm{FeCl}_{3}\right)$, and microencapsulated ferrous sulfate at level of $80 \mathrm{mg} \cdot \mathrm{kg}^{-1}$ with or without L-ascorbic acid at a level of $150 \mathrm{mg} \cdot \mathrm{kg}^{-1}$. The chemical compositions, free fatty acids (FFAs), calcium, iron, oxidation products, and the sensory aspects of the treatments were evaluated. The FFAs were determined by gas chromatography, iron, and calcium were determined by atomic absorption, and oxidation products were analyzed spectrophoto metrically using the thiobarbituric acid (TBA) test. No significant difference $(P>0.05)$ was found between chemical composition (fat, moisture, protein, ash, acidity), FFAs, and calcium of control cheeses and iron or iron-ascorbic acid fortified cheeses. Iron content was significantly different in iron or iron and ascorbic acid fortified cheeses compared to that in control ones. The treatment fortified with microencapsulated iron and ascorbic acid showed the lowest TBA value and the best scores for sensory evaluation. Results demonstrated that fortification of cheese with $80 \mathrm{mg} \cdot \mathrm{kg}^{-1}$ microencapsulated iron and $150 \mathrm{mg} \cdot \mathrm{kg}^{-1}$ L-ascorbic acid is technically feasible. Only a small increase in lipid oxidation, measured by TBA value, was caused by iron fortification; however, no significant off-flavor was detected by trained sensory panelists.
\end{abstract}

Keywords Fortification · Iron · Feta cheese · Ascorbic acid

Maryam Jalili

maryamjalili@yahoo.com; Jalili@standard.ac.ir

1 Department of Food Industries and Agriculture Research, Standard Research Institute, Karaj, Iran 


\section{Introduction}

Iron deficiency, as the most common worldwide form of micronutrient malnutrition, together with vitamin A and iodine deficiency, affects at least one third of the world's population, the majority of who are in developing countries. According to WHO mortality data, around 0.8 million deaths $(1.5 \%$ of the total) can be attributed to iron deficiency each year (WHO/FAO 2006).

To combat iron deficiency, food fortification strategy is widely considered to be the most practical and cost-effective prevention program (Hurrell 2002). As a rule, in food fortification strategies, an important requirement is that the fortified food needs to be cost-effective, to exhibit high nutritional value, and to be consumed in adequate amounts by a large proportion of the target individuals in a population (WHO/FAO 2006). Therefore, dairy products are attractive food vehicles for iron fortification since they have high nutritional value but low iron content. Moreover, dairy products are massively consumed by the general population, especially children, who are a high-risk group with regard to iron deficiency. A number of studies have been conducted on different aspects of iron fortification of dairy products, namely, yogurt (Askari and Bolandi 2013; El-Kholy et al. 2011; Azzam 2009; Simova et al. 2008), cheese (Kwak et al. 2003a), and milk (Gamal El-Din et al. 2012; Sazawal et al. 2010; Abbasi and Azari 2011).

Feta cheese is one of the most popular soft cheeses in some parts of the world such as Greece, Italy, Germany, and Iran. Feta cheese, with high worldwide consumption, is an excellent source of calcium and protein, but as a typical dairy product, it contains very low amount of iron. Therefore, fortification of cheese with iron would help to meet this nutritional need. However, to the best of the researcher's knowledge, no research on iron fortification of Feta cheese is available in the published literature.

Iron salts are widely used in food fortification; however, they have two oxidation states $\left(\mathrm{Fe}^{2+}\right.$ and $\left.\mathrm{Fe}^{3+}\right)$, which have the disadvantage of freely interacting with the constitutive elements of milk and may alter its organoleptic properties. When iron is added as $\mathrm{FeCl}_{2}$ or $\mathrm{FeCl}_{3}$ to skim milk, it is bound to the colloidal phase at about $80-90 \%$ (King et al. 1959; Gaucheron et al. 1997). Microencapsulation is a developed technology in food fortification, and it prevents the micronutrients from undesirable interaction with food components. It has been reported that the microencapsulated ferrous sulfate has the same bioavailability as ferrous sulfate but has the advantage of keeping the iron from reacting with the food vehicle and preventing the undesirable interactions which happen when conventional ferrous sulfate is used (Gaucheron 2000).

The enhancing effects of ascorbic acid on the absorption of non-heme iron have been demonstrated in a large number of studies using radioisotopes to measure iron absorption (Lynch and Stoltzfus 2003). Therefore, the aim of the current study was to examine the effect of iron compound, including ferrous sulfate $\left(\mathrm{FeSO}_{4}\right)$, ferric chloride $\left(\mathrm{FeCl}_{3}\right)$, and microencapsulated ferrous sulfate with or without L-ascorbic acid on the chemical composition, free fatty acids (FFAs), oxidation products, and sensory aspects of fortified Feta cheese. 


\section{Materials and methods}

\subsection{Chemicals}

Ferrous sulfate (36.9\% iron), ferric chloride (20.5\% iron), and microencapsulated ferrous sulfate (16\% iron) were supplied from Dr. Paul Lohman (Emmerthal, Germany) by Akbarieh Co. (Tehran, Iran). Based on the product data sheet, the ferrous sulfate was microencapsulated with approximately $50 \%$ vegetable fats and particle size ranged from 0.1 to $0.8 \mathrm{~mm}$. Food grade L-ascorbic acid, thiobarbituric acid, and the stock standard solution of iron and calcium (1000 mg. $\left.\mathrm{L}^{-1}\right)$ were purchased from SigmaAldrich (St. Louis, MO, USA). All chemicals were of analytical reagent grade. The working standard solutions were prepared by dilution of the proper amount of this stock solution with $1 \%(v / v)$ nitric acid and used for preparing calibration curve. Deionized water was used throughout the experiments.

\subsection{Manufacture of Feta cheese}

Bulk cow milk was supplied from the Iran dairy industries (Pegah) and standardized to $3.0 \%(w / w)$ fat by mixing skim milk and cream. The cheese making process was done according to Anifantakis's method (1991) with some modifications. Milk (8 kg) was pasteurized at $72{ }^{\circ} \mathrm{C}$ for $30 \mathrm{~s}$. A starter culture, containing Streptococcus thermophilus and Lactobacillus delbrueckii subsp. bulgaricus 1:1 (Hansen's Laboratorium, Copenhagen, Denmark), was added at $37-38{ }^{\circ} \mathrm{C}$. Then, $\mathrm{CaCl}_{2}$ solution was added at a rate of $1 \mathrm{~mL} . \mathrm{kg}^{-1}$ of milk. After $20 \mathrm{~min}$, commercial rennet powder (Hansen's Laboratorium, Copenhagen, Denmark) was added and mixed thoroughly. Coagulation was formed in about $60 \mathrm{~min}$, and the resulted curd was then cut into small cubes $(2.5 \mathrm{~cm})$ which were allowed to rest for $20 \mathrm{~min}$. Finally, the curd was drained and immersed in $20-22 \%(w / v)$ brine solution for $16-18 \mathrm{~h}$. To complete ripening period, the curd was stored at $4-6{ }^{\circ} \mathrm{C}$ for 60 days. In all treatments, excluding the control one, iron compound and ascorbic acid were added immediately after adding calcium chloride. The cheese making experiment was triplicate on different days. Then, chemical composition (namely fat content, moisture, protein, ash, and acidity), FFAs, calcium, iron, and sensory attributes were determined after 60-day ripening, while the thiobarbituric acid (TBA) values were measured at $1,15,30,45$, and 60 days after manufacturing.

\subsection{Iron recovery and treatments}

In a preliminary study, the recovery of iron in Feta cheese, made from iron-fortified milk, was measured. Milk ( $8 \mathrm{~kg}$ ) was fortified with each iron compound (ferrous sulfate, ferric chloride, and microencapsulated ferrous sulfate) with regard to percentage of iron and was used for Feta cheese preparation. The resulted cheese samples were analyzed then for iron contents, and recovery of iron was measured.

\subsection{Experimental design}

At the first step of the study, Feta cheese was fortified with 40, 60, 80, and $100 \mathrm{mg} \cdot \mathrm{kg}^{-1}$ of iron (data not shown). Promising results were obtained for 40 
$80 \mathrm{mg} \cdot \mathrm{kg}^{-1}$, while Feta cheese fortified with more than $80 \mathrm{mg} \cdot \mathrm{kg}^{-1}$ of iron showed adverse effects on sensory evaluation. In the other hand, since the recommended dietary allowance (RDA) of iron is about 8 and $20 \mathrm{mg}^{- \text {day }^{-1}}$ for men and women, respectively, it is assumed that if a person takes $50 \mathrm{~g}$ day $^{-1}$ of Feta cheese fortified with 80 mg. $\mathrm{kg}^{-1}$, about $20 \%$ of RDA will be met for women. Hence, in the current study, Feta cheese samples were fortified with $80 \mathrm{mg} \cdot \mathrm{kg}^{-1}$. Moreover, based on the previous researches (Kim et al. 2003; Peng et al. 2005), $150 \mathrm{mg} \cdot \mathrm{kg}^{-1}$ of ascorbic acid was added to the cheese samples.

Based on the recovery values obtained from the preliminary study, seven different treatments were prepared with fresh cow milk as follows: (1) no addition as control group (C), (2) $80 \mathrm{mg} \cdot \mathrm{kg}^{-1}$ ferrous sulfate (FS), (3) $80 \mathrm{mg} \cdot \mathrm{kg}^{-1}$ ferric chloride (FC), (4) $80 \mathrm{mg} \cdot \mathrm{kg}^{-1}$ microencapsulated iron (MC), (5) $80 \mathrm{mg} \cdot \mathrm{kg}^{-1}$ ferrous sulfate and 150 mg.kg ${ }^{-1}$ L-ascorbic acid (FSVC), (6) 80 mg.kg ${ }^{-1}$ ferric chloride and 150 mg.kg ${ }^{-1}$ L-ascorbic acid (FCVC), and (7) $80 \mathrm{mg} \cdot \mathrm{kg}^{-1}$ microencapsulated iron and $150 \mathrm{mg} \cdot \mathrm{kg}^{-1} \mathrm{~L}-$ ascorbic acid (MCVC=80 mg.kg-1 microencapsulated iron and $150 \mathrm{mg} . \mathrm{kg}-1 \mathrm{~L}$-ascorbic acid). Each treatment was prepared in triplicate. Cheese samples ( $1 \mathrm{~kg}$ for each analysis) were transferred to the lab and analyzed for chemical composition, sensory attributes, calcium, iron, and FFAs after 60-day ripening, while the TBA values were determined at $1,15,30$, and 60 days after manufacturing.

\subsection{Chemical composition}

Cheese was analyzed for fat, moisture, protein, ash, and acidity using the methods of Association of Official Analytical Chemists (AOAC 1990). Fat was determined by the Gerber method and the Gerber-Van Gulik method in milk and cheese, respectively. The protein was determined by the Kjeldahl method. For all Kjeldahl determinations, a KjelDigester K-446/K-449 digestion unit and a K-350/K-355 distillation unit (BUCHI, Labortechnik AG, Switzerland) were used. The acidity of cheese was determined by the Dornic method and expressed as percentage of lactic acid. All analyses were carried out in triplicate.

\subsection{Determination of iron and calcium}

Iron and calcium were determined in cheese samples as described by Favretto (1990) followed with some modifications. Ten grams of cheese samples was accurately weighed in a silica dish and dried overnight at $80{ }^{\circ} \mathrm{C}$. Then, $2 \mathrm{~mL}$ of nitric acid $(2 \mathrm{~N})$ was added, and the solutions were dried on a thermostatic hotplate. The samples were subsequently placed in furnace for $1 \mathrm{~h}$. After cooling, $5 \mathrm{~mL}$ nitric acid $(2 \mathrm{~N})$ and $20 \mathrm{~mL}$ nitric acid $(0.1 \mathrm{~N})$ were added and stirred thoroughly. The mixture was carefully transferred to a 50 -mL volumetric flask and made up to volume with distilled de-ionized water. The amounts of iron and calcium were determined with a GBC Model 904 Atomic absorption spectrophotometer (Melbourne, Australia). A 7.5-cm one-slot burner head and standard air-acetylene flame were used. Measurements were made using the hollow cathode lamps at the wavelengths of 324 and $422.7 \mathrm{~nm}$, for iron and calcium, respectively. Calibration curves of absorbance versus iron and calcium concentration were then plotted and subsequently used for the determination of iron in cheese samples. 


\subsection{Determination of TBA}

Oxidation products were analyzed spectrophotometrically using the TBA test (Lee et al. 2003). The reagent for TBA test was prepared by mixing equal volumes of freshly prepared TBA $(0.025 \mathrm{M})$, which was neutralized with $\mathrm{NaOH}$ and $2 \mathrm{M} \mathrm{H}_{3} \mathrm{PO}_{4} / 2 \mathrm{M}$ citric acid. One gram of cheese samples was diluted with $100 \mathrm{~mL}$ distilled water, and $5 \mathrm{~mL}$ of the mixture was added to a glass centrifuge tube and mixed thoroughly with $2.5 \mathrm{~mL}$ TBA reagent. The mixture was heated immediately in a boiling water bath for exactly $10 \mathrm{~min}$ and cooled on ice. Ten-milliliter cyclohexanone and $1 \mathrm{~mL}$ of $4 \mathrm{M}$ ammonium sulfate were added and centrifuged. The red pigment was extracted into butanol, and absorbance was measured at $535 \mathrm{~nm}$ in a 1-cm light path using a T $80 \mathrm{UV} /$ vis spectrophotometer (ChromoTek GmbH, Germany). All measurements were run in triplicate.

\subsection{Sensory analysis}

The evaluated attributes included taste (bitterness, acidity, astringency, and metallic), flavor, texture, color, and overall acceptability. Seven trained sensory panelists randomly evaluated the coded cheeses. Texture and color were evaluated on a five-point scale $(1=$ poor to 5 =excellent). Typical Feta cheese flavor, astringency, acidic, metallic, and bitterness were scored on a five-point scale $(1=$ low intensity to $5=$ high intensity). The samples were presented at random and evaluated separately.

\subsection{Analysis of FFAs}

Extraction and determination of free fatty acids (FFAs) were performed using gas chromatography based on the method described by International Standard Organization (ISO 15885, IDF 184, 2002). Cheese (1 g) sample was placed in a screw-capped test tube, and $2 \mathrm{~mL}$ of $2 \mathrm{M} \mathrm{NaHSO}_{4}$ and $5 \mathrm{~mL}$ hexane were added to the tube. The tube mixture was shaken for 3 min using a vortex mixer. Then, $0.5 \mathrm{~g} \mathrm{NaHSO} 4$ was added to the tube and centrifuged at $1015 \times g$ for $5 \mathrm{~min}$. The aliquot of the supernatant was used for gas chromatographic analysis. FFA concentrations were quantified using a gas chromatograph (YL 6000, Korea) equipped with a capillary column (Varian/CP Sil $88 ; 60 \mathrm{~m} \times 0.25 \mathrm{~mm}$ i.d. $\times 0.26 \mu \mathrm{m}$ ) and a flame ionization detector (FID). Injector and detector temperatures were 280 and $300{ }^{\circ} \mathrm{C}$, respectively. Oven temperature was programmed from 50 to $195{ }^{\circ} \mathrm{C}$ at a rate of $5^{\circ} \mathrm{C}$ per minute, with initial and final hold times of 2 and $40 \mathrm{~min}$, respectively. The run time was $65 \mathrm{~min}$. The injection mode was splitless for $1 \mathrm{~min}$, and the injection volume was $0.8 \mu \mathrm{L}$. Analyses were carried out in triplicate.

\subsection{Statistical analysis}

Data from each experiment were analyzed by one-way analysis of variance (ANOVA) using a Minitab v.14 statistical package. Comparison of the means was conducted with post hoc Tukey's test. Differences of $P<0.05$ were considered to be significant. 


\section{Results and discussion}

\subsection{Recovery of iron in cheese}

In the preliminary study, Feta cheese curd was made from iron-fortified milk. Iron recovery in cheese samples was $86 \pm 5 \%$ for ferrous sulfate, $79 \pm 6 \%$ for ferric chloride, and $61 \pm 6 \%$ for microencapsulated ferrous sulfate. Microencapsulated ferrous sulfate showed the lowest recovery, which may be related to lower density of this compound compared to milk. The microcapsules were lost during whey draining. Similarly, Jackson and Lee (1992) reported that less iron was retained in Havarti cheese curd when milk was fortified with microencapsulated iron than when free $\mathrm{FeCl}_{3}$ was used (65 versus 90\% retention). Zhang and Mahoney (1989) recovered $71-81 \%$ of iron in cheddar cheese made with ferric chloride-fortified milk.

\subsection{Chemical composition, iron, and calcium}

The composition of all treatments has been presented in Table 1. No significant difference $(P>0.05)$ was found between chemical composition (fat, moisture, protein, ash, and acidity) of control cheeses and that of iron or iron-ascorbic acid-fortified cheeses, suggesting that the type of iron salt and ascorbic acid did not significantly affect the chemical composition of Feta cheese. The compositions of all treatments were in agreement with the composition recommended by Codex Alimentarius Commission, "Standard for Cheese in Brine" (Codex 1999).

The iron and calcium contents were determined after 60-day ripening. The iron content ranged from $71.3 \pm 4.9$ to $55 \pm 1.0 \mathrm{mg} \cdot \mathrm{kg}^{-1}$ for $\mathrm{FC}$ and MCVC, respectively, while it was only $4.8 \pm 0.8 \mathrm{mg} . \mathrm{kg}^{-1}$ in control cheeses. The calcium content ranged from $484.7 \pm 4.6$ to $497.0 \pm 6.0 \mathrm{mg} . \mathrm{kg}^{-1}$. There were no significant differences between calcium contents in six treatments and control ones.

Table 1 Mean chemical composition, iron, and calcium content of iron-fortified Feta cheese $(n=3)$

\begin{tabular}{|c|c|c|c|c|c|c|c|}
\hline Treatment & $\begin{array}{l}\text { Iron } \\
\left(\mathrm{mg} \cdot \mathrm{kg}^{-1}\right)\end{array}$ & $\begin{array}{l}\text { Calcium } \\
\left(\mathrm{mg} . \mathrm{kg}^{-1}\right)\end{array}$ & Fat $(\%)$ & $\begin{array}{l}\text { Moisture } \\
(\%)\end{array}$ & $\begin{array}{l}\text { Protein } \\
(\%)\end{array}$ & Ash (\%) & Acidity \\
\hline $\mathrm{C}$ & $4.8 \pm 0.8 \mathrm{~b}$ & $496.3 \pm 7.4 \mathrm{a}$ & $34.3 \pm 2.1 \mathrm{a}$ & $54.0 \pm 2.0 \mathrm{a}$ & $17.7 \pm 1.5 \mathrm{a}$ & $3.6 \pm 0.2 \mathrm{a}$ & $1.4 \pm 0.2 \mathrm{a}$ \\
\hline FS & $70.7 \pm 2.5 \mathrm{a}$ & $484.7 \pm 4.6 \mathrm{a}$ & $34.7 \pm 1.5 \mathrm{a}$ & $55.0 \pm 1.0 \mathrm{a}$ & $18.0 \pm 2.7 \mathrm{a}$ & $3.4 \pm 0.2 \mathrm{a}$ & $1.3 \pm 0.5 \mathrm{a}$ \\
\hline $\mathrm{FC}$ & $71.3 \pm 4.9 \mathrm{a}$ & $489.0 \pm 4.6 \mathrm{a}$ & $34.7 \pm 3.1 \mathrm{a}$ & $54.3 \pm 2.5 \mathrm{a}$ & $17.7 \pm 1.5 \mathrm{a}$ & $3.4 \pm 0.2 \mathrm{a}$ & $1.4 \pm 0.5 \mathrm{a}$ \\
\hline $\mathrm{MC}$ & $67.7 \pm 4.5 \mathrm{a}$ & $487.8 \pm 8.5 \mathrm{a}$ & $35.3 \pm 1.5 \mathrm{a}$ & $55.7 \pm 2.5 \mathrm{a}$ & $19.0 \pm 1.0 \mathrm{a}$ & $3.5 \pm 0.3 \mathrm{a}$ & $1.4 \pm 0.2 \mathrm{a}$ \\
\hline FSVC & $69.3 \pm 3.5 \mathrm{a}$ & $494.3 \pm 5.9 \mathrm{a}$ & $33.0 \pm 1.0 \mathrm{a}$ & $54.3 \pm 3.5 \mathrm{a}$ & $19.7 \pm 1.2 \mathrm{a}$ & $3.4 \pm 0.4 \mathrm{a}$ & $1.6 \pm 0.2 \mathrm{a}$ \\
\hline FCVC & $70.0 \pm 6.2 \mathrm{a}$ & $497.0 \pm 6.0 \mathrm{a}$ & $37.0 \pm 1.0 \mathrm{a}$ & $56.3 \pm 2.3 \mathrm{a}$ & $18.3 \pm 3.2 \mathrm{a}$ & $3.5 \pm 0.2 \mathrm{a}$ & $1.6 \pm 0.3 \mathrm{a}$ \\
\hline MCVC & $68.7 \pm 3.2 \mathrm{a}$ & $496.7 \pm 4.2 \mathrm{a}$ & $32.3 \pm 1.5 \mathrm{a}$ & $54.7 \pm 2.1 \mathrm{a}$ & $18.0 \pm 1.0 \mathrm{a}$ & $3.2 \pm 0.3 \mathrm{a}$ & $1.4 \pm 0.2 \mathrm{a}$ \\
\hline
\end{tabular}

Means within column sharing the same small letter are not significantly different $(P<0.05)$

$C$ control, $F S 80 \mathrm{mg} \cdot \mathrm{kg}^{-1}$ ferrous sulfate, $F C 80 \mathrm{mg} \cdot \mathrm{kg}^{-1}$ ferric chloride, $M C 80 \mathrm{mg} . \mathrm{kg}^{-1}$ microencapsulated, FSVC $80 \mathrm{mg} \cdot \mathrm{kg}^{-1}$ ferrous sulfate and $150 \mathrm{mg} \cdot \mathrm{kg}^{-1}$ L-ascorbic acid, FCVC $80 \mathrm{mg} . \mathrm{kg}^{-1}$ ferric chloride and 150 mg. $\mathrm{kg}^{-1}$ L-ascorbic acid, MCVC $80 \mathrm{mg} \cdot \mathrm{kg}^{-1}$ microencapsulated iron and $150 \mathrm{mg} \cdot \mathrm{kg}^{-1}$ L-ascorbic acid 


\subsection{TBA test during ripening}

The addition of iron to dairy products might induce oxidation of dairy fat during storage. Therefore, the effect of iron fortification on chemical oxidation in Feta cheese was measured by TBA test at 1, 15, 30, and 45 during a 60-day ripening period (Table 2).

In all of the six treatments compared with control ones, TBA values increased dramatically (approximately 8-12 times), on the first day of the experiment, showing the adverse effect of iron on lipid oxidation. The order of increasing TBA value for six treatments was as follows: $\mathrm{FC}>\mathrm{FS}>\mathrm{FSVC}>\mathrm{FCVC}>\mathrm{MC}>\mathrm{MCVC}$. However, there were no significant differences between treatment fortified with ferrous sulfate and the one fortified with ferric chloride. The TBA absorbance was significantly $(P<0.05)$ lower in cheeses fortified with microencapsulated ferrous sulfate (MC) than noncapsulated (FS) ones, indicating that encapsulated iron decreases the lipid oxidation compared with non-capsulated iron $(P<0.05)$. Similar results have been observed in related studies on other dairy products, including milk (Kwak et al. 2003b), yoghurt (Kim et al. 2003), and cheddar cheese (Kwak et al. 2003a). The TBA absorbance was significantly lower in ascorbic acid-added group, regardless of encapsulation, than those in ascorbic acid-un-added group on the first day of experiments. Ascorbic acid showed a promising effect on reducing lipid oxidation as demonstrated by previous researchers (Davidsson et al. 1998; Derman et al. 1984). The treatment fortified with microencapsulated iron and ascorbic acid showed the lowest TBA value on the first day $(0.21 \pm 0.05)$; however, it was still about four times higher than that in control one.

TBA values were increased during the 30-day ripening period, and then, a significant decrease was observed in all treatments. Such a decrease may be related to degradation of lipid oxidation products such as malondialdehyde. This is well illustrated by Zhang and Mahoney (1990) who observed that TBA values of ironfortified cheddar cheese decreased during storage.

Table 2 The TBA values $\left(\mathrm{mg}^{\mathrm{kg}} \mathrm{kg}^{-1}\right)$ in seven different treatments during 60-day ripening period $(n=3)$

\begin{tabular}{|c|c|c|c|c|}
\hline \multirow[t]{2}{*}{ Treatment } & \multicolumn{4}{|c|}{$\mathrm{TBA}($ mean $\pm \mathrm{SD})$} \\
\hline & 1 day & 15 days & 30 days & 60 days \\
\hline $\mathrm{C}$ & $0.05 \pm 0.01 \mathrm{a}$ & $0.06 \pm 0.01 \mathrm{a}$ & $0.04 \pm 0.01 \mathrm{a}$ & $0.05 \pm 0.01 \mathrm{a}$ \\
\hline FS & $0.63 \pm 0.02 \mathrm{f}$ & $0.74 \pm 0.03 \mathrm{e}$ & $0.81 \pm 0.03 \mathrm{e}$ & $0.54 \pm 0.01 \mathrm{~d}$ \\
\hline $\mathrm{FC}$ & $0.68 \pm 0.01 \mathrm{f}$ & $0.83 \pm 0.01 \mathrm{f}$ & $1.01 \pm 0.01 \mathrm{f}$ & $0.60 \pm 0.01 \mathrm{e}$ \\
\hline $\mathrm{MC}$ & $0.34 \pm 0.01 \mathrm{c}$ & $0.37 \pm 0.01 \mathrm{c}$ & $0.41 \pm 0.01 \mathrm{c}$ & $0.25 \pm 0.01 \mathrm{~b}$ \\
\hline FSVC & $0.52 \pm 0.06 \mathrm{de}$ & $0.52 \pm 0.04 \mathrm{~d}$ & $0.66 \pm 0.02 \mathrm{~d}$ & $0.43 \pm 0.06 \mathrm{c}$ \\
\hline FCVC & $0.46 \pm 0.12 \mathrm{~cd}$ & $0.71 \pm 0.06 \mathrm{e}$ & $0.84 \pm 0.05 \mathrm{e}$ & $0.51 \pm 0.11 \mathrm{~d}$ \\
\hline MCVC & $0.21 \pm 0.05 \mathrm{~b}$ & $0.27 \pm 0.02 \mathrm{~b}$ & $0.29 \pm 0.01 \mathrm{~b}$ & $0.17 \pm 0.0 .4 \mathrm{~b}$ \\
\hline
\end{tabular}

Means within column sharing the same small letter are not significantly different $(P<0.05)$

$C$ control, $F S 80 \mathrm{mg} \cdot \mathrm{kg}^{-1}$ ferrous sulfate, $F C 80 \mathrm{mg} \cdot \mathrm{kg}^{-1}$ ferric chloride, $M C 80 \mathrm{mg} . \mathrm{kg}^{-1}$ microencapsulated, FSVC $80 \mathrm{mg} \cdot \mathrm{kg}^{-1}$ ferrous sulfate and $150 \mathrm{mg} \cdot \mathrm{kg}^{-1}$ L-ascorbic acid, FCVC $80 \mathrm{mg} . \mathrm{kg}^{-1}$ ferric chloride and 150 mg. $\mathrm{kg}^{-1}$ L-ascorbic acid, MCVC $80 \mathrm{mg} \cdot \mathrm{kg}^{-1}$ microencapsulated iron and $150 \mathrm{mg} \cdot \mathrm{kg}^{-1}$ L-ascorbic acid 


\subsection{FFA analysis}

The FFAs have been considered to be very important compounds for Feta cheese flavor because, in addition to their direct contribution to cheese flavor, fatty acids are also important precursors for the production of volatile flavor compounds such as alcohols, esters, aldehydes, ketones, and lactones (Abdelaziz and Ahmed Hamid 2013). Therefore, the production of FFA profile was considered to be an important aspect in this study. The FFA compositions (area \%) of all seven cheese treatments, as determined by gas chromatography, are shown in Table 3. The results indicated that there were no significant differences in FFA contents (C4 to C20) of all seven treatments after 60 days.

These results revealed that lipolysis process, which contributes to the development of the short-chain FFA, in iron-fortified cheese, was not different from that in control sample.

\subsection{Sensory analysis}

The sensory characteristics (bitterness, acidity, astringency, metallic taste, flavor, texture, color, and overall acceptability) in the six treatments and control cheeses, evaluated by seven trained panels after 60 days, are shown in Table 4.

There were no significant differences between treatments and control one for bitterness, acidic taste, astringency, and texture, while all metallic taste, Feta cheese flavor, color, and overall acceptability were statistically $(P<0.05)$ affected by the iron

Table 3 Concentration of free fatty acids (FFAs) in seven treatments after 60-day ripening period $(n=3)$

Treatment $($ mean $\pm \mathrm{SD})$

\begin{tabular}{llllllll}
\hline FFA & C & FS & FC & MC & FSVC & FCVC & MCVC \\
\hline C4:0 & $1.53 \pm 0.15$ & $1.56 \pm 0.15$ & $1.6 \pm 0.1$ & $1.63 \pm 0.15$ & $1.6 \pm 0.2$ & $1.6 \pm 0.1$ & $1.63 \pm 0.15$ \\
C6:0 & $0.53 \pm 0.05$ & $0.5 \pm 0.1$ & $0.53 \pm 0.06$ & $0.63 \pm 0.06$ & $0.6 \pm 0.1$ & $0.62 \pm 0.06$ & $0.66 \pm 0.05$ \\
C8:0 & $0.4 \pm 0.1$ & $0.36 \pm 0.11$ & $0.36 \pm 0.06$ & $0.4 \pm 0.1$ & $0.37 \pm 0.05$ & $0.37 \pm 0.05$ & $0.43 \pm 0.05$ \\
C10:0 & $1.33 \pm 0.15$ & $1.4 \pm 0.1$ & $1.26 \pm 0.12$ & $1.4 \pm 0.2$ & $1.4 \pm 0.1$ & $1.3 \pm 0.1$ & $1.43 \pm 0.06$ \\
C12:0 & $1.93 \pm 0.15$ & $2.13 \pm 0.15$ & $2.06 \pm 0.15$ & $2.03 \pm 0.15$ & $1.93 \pm 0.15$ & $2.06 \pm 0.15$ & $1.89 \pm 0.12$ \\
C14:0 & $9.7 \pm 0.61$ & $9.8 \pm 0.76$ & $10.8 \pm 0.52$ & $11.2 \pm 0.75$ & $10.4 \pm 0.53$ & $10.1 \pm 1.01$ & $9.9 \pm 1.05$ \\
C15:0 & $1.2 \pm 0.1$ & $1.17 \pm 0.12$ & $1.13 \pm 0.06$ & $1.27 \pm 0.06$ & $1.23 \pm 0.05$ & $1.16 \pm 0.12$ & $1.06 \pm 0.31$ \\
C16:0 & $32.13 \pm 0.38$ & $31.7 \pm 0.53$ & $32.17 \pm 0.92$ & $31.8 \pm 0.7$ & $32.17 \pm 0.91$ & $32 \pm 0.3$ & $31.1 \pm 1.05$ \\
C16:1c & $3.57 \pm 0.21$ & $3.9 \pm 0.26$ & $3.73 \pm 0.50$ & $3.8 \pm 0.36$ & $3.6 \pm 0.44$ & $3.8 \pm 0.4$ & $3.6 \pm 0.4$ \\
C17:0 & $0.63 \pm 0.05$ & $0.66 \pm 0.06$ & $0.53 \pm 0.06$ & $0.56 \pm 0.12$ & $0.57 \pm 0.06$ & $0.63 \pm 0.05$ & $0.56 \pm 0.11$ \\
C18:0 & $10.73 \pm 0.47$ & $11.2 \pm 0.89$ & $11.07 \pm 0.70$ & $11.06 \pm 0.89$ & $0.83 \pm 0.40$ & $10.97 \pm 0.67$ & $10.73 \pm 0.50$ \\
C18:2c & $2.53 \pm 0.35$ & $2.5 \pm 0.36$ & $2.67 \pm 0.21$ & $2.53 \pm 0.25$ & $2.43 \pm 0.32$ & $2.33 \pm 0.31$ & $2.1 \pm 0.3$ \\
C18:3c & $0.83 \pm 0.58$ & $0.73 \pm 0.15$ & $0.83 \pm 0.21$ & $0.73 \pm 0.23$ & $0.85 \pm 0.23$ & $0.75 \pm 0.12$ & $0.95 \pm 0.17$ \\
C20:1 & $0.67 \pm 0.06$ & $0.7 \pm 0.17$ & $0.67 \pm 0.15$ & $0.6 \pm 0.1$ & $0.73 \pm 0.12$ & $0.66 \pm 0.05$ & $0.56 \pm 0.06$ \\
\hline
\end{tabular}

$C$ control, $F S 80 \mathrm{mg} \cdot \mathrm{kg}^{-1}$ ferrous sulfate, $F C 80 \mathrm{mg} \cdot \mathrm{kg}^{-1}$ ferric chloride, $M C 80 \mathrm{mg} . \mathrm{kg}^{-1}$ microencapsulated, FSVC $80 \mathrm{mg} \cdot \mathrm{kg}^{-1}$ ferrous sulfate and $150 \mathrm{mg} \cdot \mathrm{kg}^{-1}$ L-ascorbic acid, FCVC $80 \mathrm{mg} \cdot \mathrm{kg}^{-1}$ ferric chloride and 150 mg.kg ${ }^{-1}$ L-ascorbic acid, MCVC 80 mg.kg ${ }^{-1}$ microencapsulated iron and 150 mg.kg ${ }^{-1}$ L-ascorbic acid 


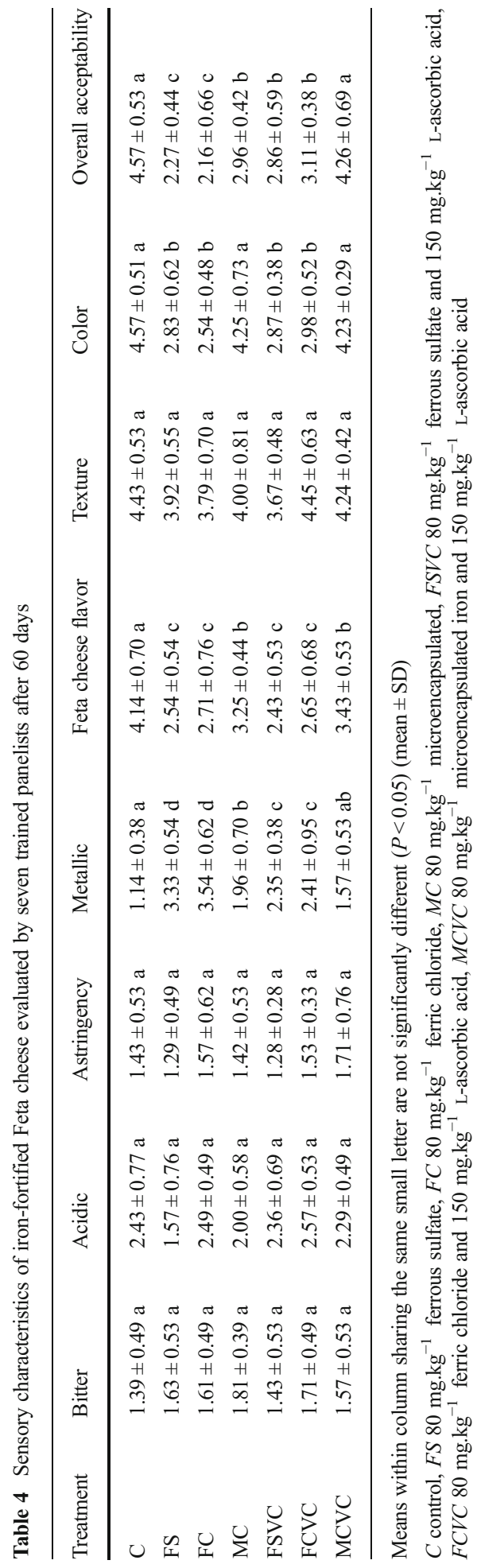


source. Iron fortification caused increases in metallic taste scores ranging from 1.57 \pm 0.53 to $3.54 \pm 0.62$ for treatments containing microencapsulated iron and ascorbic acid (MCVC) and treatment fortified with ferric chloride (FC), respectively. While, there was no significant difference between the control sample and MCVC. The "Feta cheese flavor" scores in all of the treatments, except for the treatment fortified with microencapsulated iron and ascorbic acid (MCVC), were lower than those in control group $(P<0.05)$. The color of all treatments was also affected by iron source. The highest color score (the better color) was found for treatment fortified with microencapsulated iron $(4.25 \pm 0.73)$. There was no significant difference between color of ironfortified treatments and that of iron-ascorbic acid ones. It seems that the addition of ascorbic acid does not show any promising effect on the color of fortified cheeses. The overall acceptability was also affected by the iron added. Between six iron-fortified treatments, the best score $(4.26 \pm 0.69)$ was found for MCVC which was comparable with that of control sample $(4.57 \pm 0.53)$.

\section{Conclusion}

The current study demonstrated that fortification of cheese with $80 \mathrm{mg} \cdot \mathrm{kg}^{-1}$ microencapsulated iron and $150 \mathrm{mg} \cdot \mathrm{kg}^{-1} \mathrm{~L}$-ascorbic acid is technically feasible with only a small increase in lipid oxidation, measured by TBA value. No off-flavor was detected by trained sensory panelists. Ascorbic acid showed a promising impact on reducing unfavorable effects of iron.

Acknowledgments The author is grateful to Iran Dairy Industries (Pegah) for funding this research and Akbarieh Co. for kindly supplying the chemicals. The research was also supported by the National Nutrition and Food Technology Research Institute (Iran, Shahid Beheshti University).

\section{Compliance with ethical standards}

Conflict of interest The author declares that there are no conflicts of interest.

\section{References}

Abbasi S, Azari S (2011) Efficiency of novel iron microencapsulation techniques: fortification of milk. Int J Food Sci Technol 46:1927-1933

Abdelaziz EAO, Ahmed Hamid OI (2013) Characterization of free fatty acids contents of Sudanese white cheese during storage. J Adv Sci Res 4:22-26

Anifantakis EM (1991) Traditional Feta cheese. In: Robinson RK, Tamime AY (eds) Feta and related cheeses. Ellis Horwood, NY, pp 49-69

AOAC (1990) Official methods of analysis, 15th edn. Association of Official Analysis Chemists Inc., USA

Askari N, Bolandi M (2013) Assessment of iron fortification influence on organoleptics and physic-chemical properties of yogurt. J Chemical Health Risk 3:1-8

Azzam MA (2009) Effect of fortification with iron-whey protein complex on quality of yoghurt. Egyptian J Dairy Sci 37:55-63

Codex Alimentarius Commission A17 (1999) Standard for cheeses in brine. Codex Stand. 208 
Davidsson L, Walczyk T, Morris A, Hurrell RF (1998) Influence of ascorbic acid on iron absorption from an iron-fortified, chocolate-flavored milk drink in Jamaican children. Am J Clin Nutr 67:873-877

Derman DP, Mills W, Mayet F (1984) The relative effect of ascorbic acid on iron absorption from soy-based and milk-based infant formulas. Am J Clin Nutr 40:522-527

El-Kholy AM, Osman M, Gouda A, Ghareeb WA (2011) Fortification of yoghurt with iron. World J Dairy Food Sci 6:59-165

Favretto LG (1990) Investigation of trace element content of cheese. Food Addit Contam 7:425-432

Gamal El- Din AM, Hassan ASH, El- Behairy SA, Mohamed EA (2012) Impact of zinc and iron salts fortification of Buffalo's milk on the dairy product. World J Dairy Food Sci 6:21-27

Gaucheron F (2000) Iron fortification in dairy industry. Trends Food Sci Technol 11:403-409

Gaucheron F, Le Graet Y, Raulot K, Piot M (1997) Physicochemical characterization of iron-supplemented skim milk. Int Dairy J 7:141-148

Hurrell RF (2002) Fortification: overcoming technical and practical barriers. J Nutr 132:806S-812S

ISO 15885, IDF 184: First edition (2002) Milk fat-determination of the fatty acid composition by gas-liquid chromatography

Jackson LS, Lee K (1992) Fortification of cheese with microencapsulated iron. Cultured Dairy Products J 56: 1-7

Kim SJ, Ahn J, Seok JS, Kwak HS (2003) Microencapsulated iron for drink yogurt fortification. AsianAustralasian J Anim Sci 16:581-587

King RL, Luick JR, Litman II, Jennings WG, Dunkley WL (1959) Distribution of natural and added copper and iron in milk. J Dairy Sci 42:780-790

Kwak HS, Ju YS, Ahn HJ, Ahn J, Lee S (2003a) Microencapsulated iron fortified and flavor development in cheddar cheese. Asian-Australasian J Anim Sci 16:1205-1211

Kwak HS, Yang KM, Ahn J (2003b) Microencapsulated iron for milk fortification. J Agric Food Chem 51: $7770-7774$

Lee JB, Ahn J, Kwak HS (2003) Microencapsulated ascorbic acid for milk fortification. Arch Pharm Res 26: 575-580

Lynch SR, Stoltzfus RJ (2003) Iron and ascorbic acid: proposed fortification levels and recommended iron compounds. J Nutr 133:2978S-2984S

Peng LS, Omar H, Abdullah AS, Dahalan R, Ismail M (2005) The effect of calcium, ascorbic acid and tannic acid on iron availability from Arthrospira platensis by caco-2 cell model. Mal J Nutr 11:177-188

Sazawal S, Dhingra U, Dhingra P, Hiremath G, Sarkar A, Dutta A, Menon VP, Black RE (2010) Micronutrient fortified milk improves iron status, anemia and growth among children $1-4$ years: a double masked, randomized, controlled trial. PLoS ONE 5, e 12167

Simova E, Ivanov G, Simov Z (2008) Growth and activity of Bulgarian yogurt starter culture in iron-fortified milk. J Ind Microbiol Biotechnol 35:1109-1115

WHO/FAO (2006) Guidelines on food fortification with micronutrients (Lindsay A, de Benoist B, Dary O, Hurrell, R. (Eds))

Zhang DJ, Mahoney AW (1989) Effect of iron fortification on quality of cheddar cheese. J Dairy Sci 72:322332

Zhang DJ, Mahoney AW (1990) Effect of iron fortification on quality of cheddar cheese. Effects of aging and fluorescent light on pilot scale cheeses. J Dairy Sci 73:2252-2258 